\title{
ChemComm
}

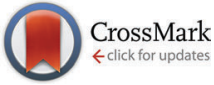

Cite this: Chem. Commun., 2014 50, 15589

Received 28th August 2014, Accepted 22nd October 2014

DOI: $10.1039 / \mathrm{c} 4 \mathrm{cc} 06649 a$

www.rsc.org/chemcomm

\section{Electrically-driven modulation of surface-grafted RGD peptides for manipulation of cell adhesion $\dagger$}

\author{
Minhaj Lashkor, ${ }^{a}$ Frankie J. Rawson, ${ }^{b}$ Alex Stephenson-Brown, ${ }^{a}$ Jon A. Preece ${ }^{c}$ and \\ Paula M. Mendes*a
}

Reported herein is a switchable surface that relies on electrically-induced conformational changes within surface-grafted arginine-glycineaspartate (RGD) oligopeptides as the means of modulating cell adhesion.

Stimuli-responsive surfaces that are capable of modulating their biological properties in response to an external stimuli, including temperature, ${ }^{1,2}$ light, $^{3}$ magnetic field ${ }^{4}$ and electrical potential, ${ }^{5-9}$ are of growing interest for a variety of biological and medical applications. $^{10,11}$ Switchable surfaces that can be controlled on-demand are playing an increasingly important part in the development of highly sensitive biosensors, ${ }^{12-15}$ novel drug delivery systems ${ }^{16-18}$ and functional microfluidic, bioanalysis, and bioseparation systems. ${ }^{19-22}$ Additionally, dynamic, synthetic surfaces that can control the presentation of regulatory signals to a cell are expected to have a significant impact in the field of tissue engineering and regenerative medicine, and to provide unprecedented opportunities in fundamental studies of cell biology. ${ }^{23,24}$ The availability of sophisticated and functional switchable surfaces is expected to emulate more complex in vivo like extracellular environments, and provide a powerful means to probe and control the dynamic interactions between the cell and its external environments.

The majority of studies on stimuli-responsive surfaces reported to date either rely ${ }^{25-29}$ on controlling non-specific interactions (i.e., hydrophobic/hydrophilic and electrostatic) of the biomolecules with the active surface, or have focused ${ }^{30-32}$ on demonstrating modulation of specific biomolecular interactions using relatively simple biological systems (e.g. biotin-streptavidin) and conditions (i.e. water or buffer solutions). For example, Zareie et $a l^{30}$ fabricated a mixed self-assembled monolayer (SAM) on gold comprising oligo(ethylene glycol) (OEG) thiol molecules and shorter disulfides carrying biotin

\footnotetext{
${ }^{a}$ School of Chemical Engineering, University of Birmingham, Edgbaston, Birmingham, B15 2TT, UK. E-mail: p.m.mendes@bham.ac.uk

${ }^{b}$ Laboratory of Biophysics and Surface Analysis, School of Pharmacy, University of Nottingham, University Park, Nottingham, NG72RD, UK

${ }^{c}$ School of Chemistry, University of Birmingham, Edgbaston, Birmingham, B15 2TT, $U K$

$\dagger$ Electronic supplementary information (ESI) available: Experimental methods. See DOI: $10.1039 / \mathrm{c} 4 \mathrm{cc} 06649 \mathrm{a}$
}

end-groups that regulated the interaction between biotin and streptavidin in water. The OEG thiols were able to switch in response to a change in temperature below and above their lower critical solution temperature $\left(\operatorname{LCST}=37{ }^{\circ} \mathrm{C}\right.$ ). At $23{ }^{\circ} \mathrm{C}$ the structure of the OEG molecules was fully extended hindering the shorter biotin disulfide components. On the contrary, at $45{ }^{\circ} \mathrm{C}$ the OEG backbone collapsed, thus allowing the specific interaction between the biotin molecule on the surface and the protein streptavidin in solution. In our previous work, ${ }^{7-9}$ electrically controlled switching has been applied to regulate the conformational changes of modified positively charged oligolysine peptides tethered to a gold surface, such that biotin moieties incorporated into the oligolysines could be reversibly exposed or concealed on demand, as a function of surface potential. Switchable SAMs used to control biomolecular interactions via an electrical stimulus are particularly appealing because of their fast response times, ease of creating multiple individually addressable switchable regions on the same surface, as well as low-drive voltage and electric fields, which are compatible with biological systems. ${ }^{33}$ Our previous reported electrically switchable surface was able to control directly the biomolecular interactions between biotin and neutravidin in phosphate buffer saline (PBS) solution.

However, switchable surfaces have been scarcely used, thus far, to control biomolecular interactions on more complex systems such as those involving modulation of cell responsiveness. ${ }^{34-37}$ Jonkheijm and co-workers ${ }^{35}$ have reported a cucurbit[8]uril-based SAM system to electrochemically control the release of cells. Charged end groups on SAM surfaces have been exploited to electrically control the early stages of bacterial cell adhesion ${ }^{37}$ and form patterned surfaces with two independent dynamic functions for inducing cell migration. ${ }^{36}$ In spite of these efforts, given cellular complexity and diversity, such studies are very limited in number, as are the opportunities to further understand and control the complex interplay of events and interactions occurring within living cells.

Herein, we report on a stimuli-responsive surface that relies on electrically-induced conformational changes within surfacegrafted arginine-glycine-aspartate (RGD) oligopeptides as the means of modulating cell adhesion. RGD, which is present in most of the adhesive ECM proteins (e.g. fibronectin, vitronectin, laminin 


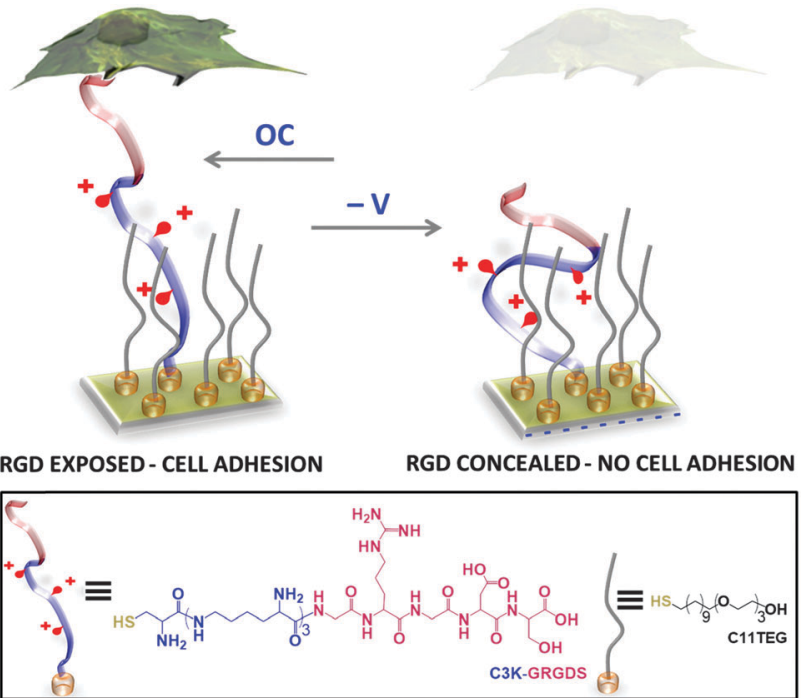

Fig. 1 Schematic of the dynamic RDG oligopeptide SAM utilised for controlling specific cellular interactions. The electrically switchable SAM exposes the RGD peptide and supports cell adhesion under open circuit (OC) conditions (no applied potential), while under an applied negative potential the RGD is concealed, inhibiting cell adhesion. Below: chemical structures of the oligopeptides (C3K-GRGDS) and oligo(ethylene glycol) thiols (C11TEG) used for SAM preparation.

and collagen), is specific for integrin-mediated cell adhesion. ${ }^{38}$ The RGD modified electrode is used here to dynamically regulate the adhesion of immune macrophage cells. The stimuli-responsive surface is fabricated on a gold surface and comprises a mixed SAM consisting of two components (Fig. 1): (i) an oligopeptide containing a terminal cysteine for attachment to the gold surface, three lysine residues as the main switching unit, and a glycine-arginine-glycineaspartate-serine (GRGDS) as the recognition motif for cell adhesion - C3K-GRGDS, and (ii) an ethylene glycol-terminated thiol (C11TEG) to space out the oligopeptides. Since the charged backbone of the oligopeptide can be potentially harnessed ${ }^{7-9}$ to induce its folding on the surface upon an application of an electrical potential, we reasoned that such conformational changes can be employed to selectively expose under open circuit (OC) conditions (bio-active state) or conceal under negative potential (bio-inactive state) the RGD to the cell and dynamically regulate cell adhesion.

Mixed SAMs of C3K-GRGDS : C11TEG were formed from a solution ratio of $1: 40$ and characterised by X-ray photoelectron spectroscopy (XPS) (Fig. S2, ESI $\dagger$ ). XPS analysis confirmed the formation of the C3K-GRGDS:C11TEG mixed monolayer and displayed signals from S, N, C and O. The chemical state of the sulphur atom was probed using the XPS spectra of the $S$ 2p emission (Fig. S2, ESI $\dagger$ ). The S 2 p spectrum (Fig. S2a, ESI $\dagger$ ) consists of two doublet peaks, with one doublet peak at $162.0 \mathrm{eV}\left(\mathrm{S} 2 \mathrm{p}_{3 / 2}\right)$ and $163.2 \mathrm{eV}\left(\mathrm{S} 2 \mathrm{p}_{1 / 2}\right)$, indicating that the sulphur is chemisorbed on the gold surface. ${ }^{39}$ A second small doublet peak can be observed at $163.8 \mathrm{eV}$ and $165.0 \mathrm{eV}$, which can be attributed to the $\mathrm{S}-\mathrm{H}$ bond, indicating a small presence of unbound sulphur. No sulphur peaks above $166 \mathrm{eV}$ were observed, indicating that no oxidised sulphur is present at the surface. The $\mathrm{N}$ 1s spectrum (Fig. S2b, ESI $\dagger$ ) can be de-convoluted into two peaks, which support the presence of the peptide on the surface. The first peak centred at $400.5 \mathrm{eV}$ is attributed to amino $\left(\mathrm{NH}_{2}\right)$ and amide $(\mathrm{CONH})$ moieties. The second peak centred at $402.8 \mathrm{eV}$ is ascribed to protonated amino groups. ${ }^{40}$ Note that no nitrogen peak was observed for pure C11TEG SAMs. The C 1s spectrum (Fig. S2c, ESI $\dagger$ ) can be de-convoluted into three peaks, which are attributed to five different binding environments. The peak at $285.0 \mathrm{eV}$ is attributed to $\mathrm{C}-\mathrm{C}$ bonds, ${ }^{41}$ while the peak at $286.7 \mathrm{eV}$ corresponds to $\mathrm{C} 1 \mathrm{~s}$ of the three binding environments of $\mathrm{C}-\mathrm{S}, \mathrm{C}-\mathrm{N}$ and $\mathrm{C}-\mathrm{O} .{ }^{41}$ The third and smaller peak $(288.6 \mathrm{eV}$ ) is assigned to the $\mathrm{C}$ 1s photoelectron of the carbonyl moiety, $\mathrm{C}=\mathrm{O} .{ }^{41}$ The O 1s spectrum (Fig. S2d, ESI $\dagger$ ) is de-convoluted into two different peaks, corresponding to two different binding environments, arising from the $\mathrm{C}-\mathrm{O}(533.3 \mathrm{eV})$ and $\mathrm{C}=\mathrm{O}(532.0 \mathrm{eV})$ bonds. $^{41}$ From integrating the area of the $\mathrm{S} 2 \mathrm{p}$ and $\mathrm{N} 1 \mathrm{~s}$ peaks and taking into consideration that the C3K-GRGDS oligopeptide consists of $15 \mathrm{~N}$ atoms and $1 \mathrm{~S}$ atom and C11TEG has no $\mathrm{N}$ and $1 \mathrm{~S}$ atom only, it was possible to infer that the ratio of C3K-GRGDS:C11TEG on the surface is $1: 10 \pm 2$. The presence of C11TEG was utilised not only to ensure sufficient spatial freedom for molecular reorientation of the surface bound oligopeptide, but also to stop non-specific binding to the surface.

The C3K-GRGDS:C11TEG mixed SAMs were shown to support adhesion of immune macrophage cells as determined by cell counting $^{42,43}$ (Fig. 2). When RAW 264.7 mouse macrophages were cultured on the C3K-GRGDS:C11TEG mixed SAM in supplemented Dulbecco's Modified Eagle Medium (DMEM), the number of cells adhered to the surface increased with incubation time, reaching $1792 \pm 157$ cells per $\mathrm{mm}^{2}$ after 24 hours. This is in contrast with the weak cell adhesion observed in two control surfaces, pure C11TEG SAMs and clean gold, in which the number of cells that adhere was $60 \%$ and $50 \%$ lower, respectively, after 24 hours (Fig. 2).

In order to demonstrate that the C3K-GRGDS:C11TEG mixed SAMs can support or resist cell adhesion on demand, the macrophage cells were cultured on the C3K-GRGDS:C11TEG mixed SAM in DMEM medium under OC conditions and applied negative potential $(-0.4 \mathrm{~V})$ for a period of $1 \mathrm{~h}$. Note that DMEM contains a mixture of inorganic salts, amino acids, glucose and vitamins. On application of the applied potential of $-0.4 \mathrm{~V}$ the number of adherent cells was 70\% less compared to the C3K-GRGDS:C11TEG mixed SAMs under

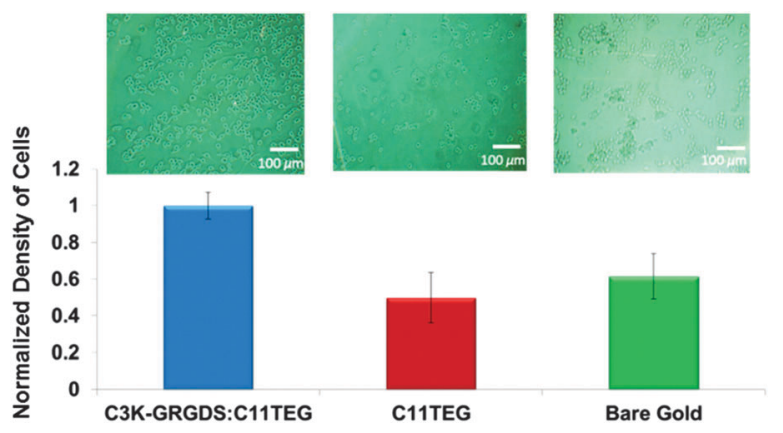

Fig. 2 Microscopic images and density of adhered cells on C3K-GRGDS: C11TEG mixed SAM, pure C11TEG SAM and bare gold surfaces that were normalized against the density of cells adherent onto the C3K-GRGDS:C11TEG mixed SAM. The surfaces were cultured in RAW 264.7 mouse macrophage cells under OC conditions for 24 hours. 


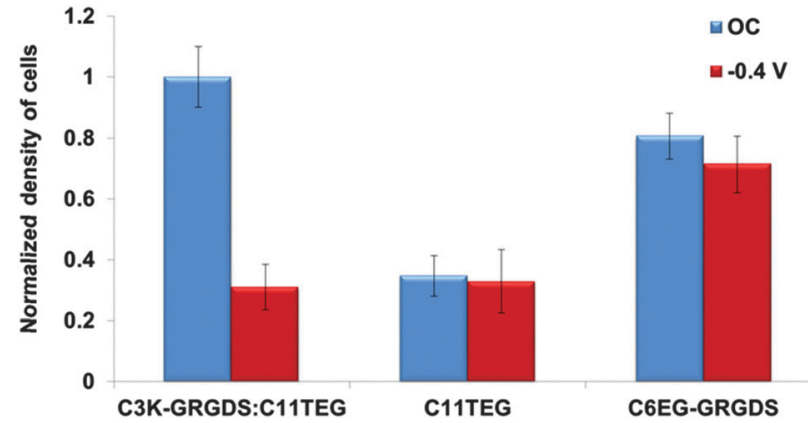

Fig. 3 Density of adhered cells on C3K-GRGDS:C11TEG, C11TEG, C6EG-GRGDS:C11TEG mixed SAMs that were normalized against the density of cells adherent onto the C3K-GRGDS:C11TEG mixed SAM. The surfaces were cultured in RAW 264.7 for $1 \mathrm{~h}$ under OC conditions or while applying $-0.4 \mathrm{~V}$

OC conditions, Fig. 3. Similar switching efficiencies have been observed in another oligopeptide system using different DMEM solutions. ${ }^{44}$ These findings suggest that the negative potential induces the conformational changes in the $\mathbf{C} 3 \mathbf{K}$ moiety of C3K-GRGDS in the SAM which in turn leads to the RGD moiety being concealed and hence reducing the binding of the cells.

Previous studies have shown that small conformational and orientational changes in proteins and peptides modulate the availability and potency of the active sites for cell surface receptors. ${ }^{45-47}$ Thus, in a similar manner, small changes in the conformation/orientation of the RGD peptide on the surface induced by application of an electrical potential are able to affect the binding activity of the peptide. Recently, we have conducted detailed theoretical ${ }^{8}$ and experimental ${ }^{9}$ studies aimed at understanding the switching mechanism of oligopeptide-based switchable surfaces, that similarly as in the case of the C3K-GRGDS:C11TEG mixed SAMs, use lysine residues to act as the switching unit. These previous studies unraveled that the surface-appended oligolysines undergo conformational changes between fully extended, partially extended and collapsed conformer structures in response to an applied positive potential, open circuit conditions and negative electrical potential, respectively. Thus, these previous findings allow us to propose that when a negative potential is applied to the GRGDS:C11TEG mixed SAM surface, the oligopeptide chain adopts a collapsed conformation on the surface and the RGD binding motif is partially embedded on the C11TEG matrix, thus showing no bioactivity ("OFF" state).

In order to verify that the changes in adhesion upon application of a negative surface potential occur due to changes in the conformational orientation of the RGD instead of cell repulsion or cell damage due to the presence of an electrical potential, control mixed SAMs were also prepared using C11TEG and a peptide where the 3 lysine residues as the switching unit were replaced by 6 non-switchable ethylene glycol units - C6EG-GRGDS (Fig. S1, ESI†). Fig. 3 demonstrates that cells adhered in similar numbers to the C11TEG and C6EG-GRGDS:C11TEG mixed SAMs under OC conditions and an applied negative potential. These results provide strong evidence that control over cell adhesion using the C3K-GRGDS:C11TEG mixed SAM is due to a conformational behaviour of the lysine-containing oligopeptide that can either expose or conceal the RGD moiety.
Cell viability was checked following application of $-0.4 \mathrm{~V}$ for $1 \mathrm{~h}$ by performing a trypan blue assay. Cells that were dead were stained blue due to a break down in membrane integrity. Incubation of the cells under a negative potential had negligible effect on cell viability, which was greater than $98 \%$. Cyclic voltammetric studies (outlined in detail in the Fig. S3, ESI $\dagger$ ) were also performed to demonstrate that no significant faradaic process occur over the potential range studied, and thus ions are not participating in redox reactions and consequently redox chemistry is not being significantly affected by application of the potential used. In agreement with other studies, ${ }^{35,36,48}$ we conclude that the electrical modulation of the surface neither affected cell viability nor induced any redox process in the medium that could have had an effect on cells.

We then addressed the question of whether the C3K-GRGDS: C11TEG surfaces could be switched between different cell adhesive states (cell-resistant and cell-adhesive states). To begin with, we investigated the switching from a cell-adhesive state to a cellresistant state, and the possibility to detach the cells from the substrate upon the application of a negative potential. Cells were incubated in the C3K-GRGDS:C11TEG mixed SAMs for $1 \mathrm{~h}$ under OC conditions, thereby exposing the RGD moiety and allowing for cell attachment. This step was followed by the application of a potential of $-0.4 \mathrm{~V}$ for $1 \mathrm{~h}$ in order to detach the cells from the surface, by concealing the RGD moieties. Cell counts showed no significant differences between the pre and post application of the $-0.4 \mathrm{~V}$, suggesting that the electrostatic force generated by the applied negative electrical potential might not be sufficient to disrupt the RGD-integrin interaction. These results were to a certain extent expected since adherent cells are able to withstand strong detachment forces due to the adhesion being mediated by multiple RGDintegrin bonds in parallel. ${ }^{49}$

In contrast, a reversal of the switching sequence demonstrated that our surfaces can be dynamically switched from a non-adhesive to cell-adhesive state. Cells were incubated in the C3K-GRGDS: C11TEG mixed SAMs for $1 \mathrm{~h}$ while holding the potential at $-0.4 \mathrm{~V}$ for $1 \mathrm{~h}$ making the RGD peptide inaccessible for recognition by the corresponding integrin. As above, the number of adherent cells when a negative potential of $-0.4 \mathrm{~V}$ was applied was $70 \%$ of the number that adhered to the C3K-GRGDS:C11TEG mixed SAMs under OC conditions, Fig. 4 . The potential was then shifted to open circuit conditions for $1 \mathrm{~h}$ on those exposed to a potential of $-0.4 \mathrm{~V}$, which resulted in a significant increase in the number of cells as a result of the exposure of the RGD moiety to the cells (Fig. 4). These values were similar to those obtained for the samples that were only incubated for 1 hour under OC conditions (Fig. 4), indicating that the surfaces were highly effective at switching from a non-adhesive to cell-adhesive state.

In summary, an electrically switchable surface has been devised and fabricated that is capable of efficiently exposing and concealing the RGD cell adhesion motif and dynamically regulate the adhesion of immune macrophage cells. This study will no doubt be useful in developing more realistic dynamic extracellular matrix models and is certainly applicable in a wide variety of biological and medical applications. For instance, macrophage cell adhesion to surfaces plays a key role in mediating immune response to foreign materials. ${ }^{50}$ Thus, development of such dynamic in vitro model 


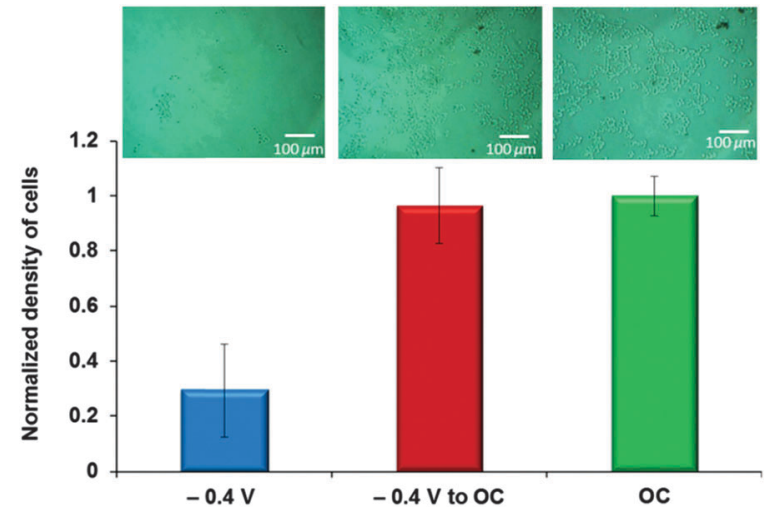

Fig. 4 Microscopic images and density of adhered cells on C3K-GRGDS: C11TEG mixed SAMs that were incubated with cells for $1 \mathrm{~h}$ while applying $-0.4 \mathrm{~V}$ and subsequently in $\mathrm{OC}$ conditions for $1 \mathrm{~h}$. The density was normalized against the density of cells adherent onto C3K-GRGDS:C11TEG mixed SAMs that were incubated with cells in $O C$ conditions for $1 \mathrm{~h}$.

systems that can control macrophage cell adhesion on demand are likely to provide new opportunities to understand adhesion signalling in macrophages ${ }^{51}$ and develop effective approaches for prolonging the life-span of implantable medical devices and other biomaterials. $^{52}$

The authors acknowledge financial support of this work by the Wellcome Trust (WT091285MA), Leverhulme Trust (F/00094/ AW and ECF/2013-603) and EPSRC (EP/K027263/1). Also, we acknowledge the University of Leeds EPSRC Nanoscience and Nanotechnology Facility (LENNF) for access to the XPS.

\section{Notes and references}

1 H. M. Zareie, C. Boyer, V. Bulmus, E. Nateghi and T. P. Davis, ACS Nano, 2008, 2, 757-765.

2 S. Balamurugan, L. K. Ista, J. Yan, G. P. Lopez, J. Fick, M. Himmelhaus and M. Grunze, J. Am. Chem. Soc., 2005, 127, 14548-14549.

3 G. B. Demirel, N. Dilsiz, M. A. Ergun, M. Cakmak and T. Caykara, J. Mater. Chem., 2011, 21, 10415-10420.

4 R. J. Mannix, S. Kumar, F. Cassiola, M. Montoya-Zavala, E. Feinstein, M. Prentiss and D. E. Ingber, Nat. Nanotechnol., 2008, 3, 36-40.

5 P. M. Mendes, K. L. Christman, P. Parthasarathy, E. Schopf, J. Ouyang, Y. Yang, J. A. Preece, H. D. Maynard, Y. Chen and J. F. Stoddart, Bioconjugate Chem., 2007, 18, 1919-1923.

6 L. Mu, Y. Liu, S. Zhang, B. H. Liu and J. Kong, New J. Chem., 2005, 29, 847-852.

7 C. L. Yeung, P. Iqbal, M. Allan, M. Lashkor, J. A. Preece and P. M. Mendes, Adv. Funct. Mater., 2010, 20, 2657-2663.

8 C. L. Yeung, X. Wang, M. Lashkor, E. Cantini, F. J. Rawson, P. Iqbal, J. A. Preece, J. Ma and P. M. Mendes, Adv. Mater. Interfaces, 2014, 1, 1300085.

9 A. Pranzetti, M. Davis, C. L. Yeung, J. A. Preece, P. Koelsch and P. M. Mendes, Adv. Mater. Interfaces, 2014, 1, 1400026.

10 P. M. Mendes, Chem. Soc. Rev., 2008, 37, 2512-2529.

11 P. M. Mendes, Chem. Soc. Rev., 2013, 42, 9207-9218.

12 F. Ricci, R. Y. Lai, A. J. Heeger, K. W. Plaxco and J. J. Sumner, Langmuir, 2007, 23, 6827-6834.

13 U. Rant, K. Arinaga, S. Scherer, E. Pringsheim, S. Fujita, N. Yokoyama, M. Tornow and G. Abstreiter, Proc. Natl. Acad. Sci. U. S. A., 2007, 104, 17364-17369.

14 C. E. Immoos, S. J. Lee and M. W. Grinstaff, J. Am. Chem. Soc., 2004, 126, 10814-10815.

15 Y. Xiao, A. A. Lubin, B. R. Baker, K. W. Plaxco and A. J. Heeger, Proc. Natl. Acad. Sci. U. S. A., 2006, 103, 16677-16680.
16 P. M. George, D. A. LaVan, J. A. Burdick, C. Y. Chen, E. Liang and R. Langer, Adv. Mater., 2006, 18, 577-588.

17 M. Pyo, G. Maeder, R. T. Kennedy and J. R. Reynolds, J. Electroanal. Chem., 1994, 368, 329-332.

18 J. M. Pernaut and J. R. Reynolds, J. Phys. Chem. B, 2000, 104, 4080-4090.

19 D. L. Huber, R. P. Manginell, M. A. Samara, B. I. Kim and B. C. Bunker, Science, 2003, 301, 352-354.

20 H. Yamanaka, K. Yoshizako, Y. Akiyama, H. Sota, Y. Hasegawa, Y. Shinohara, A. Kikuchi and T. Okano, Anal. Chem., 2003, 75, 1658-1663.

21 K. Yoshizako, Y. Akiyama, H. Yamanaka, Y. Shinohara, Y. Hasegawa, E. Carredano, A. Kikuchi and T. Okano, Anal. Chem., 2002, 74, 4160-4166.

22 K. Nagase, J. Kobayashi, A. Kikuchi, Y. Akiyama, H. Kanazawa and T. Okano, Langmuir, 2007, 23, 9409-9415.

23 M. P. Lutolf, J. L. Lauer-Fields, H. G. Schmoekel, A. T. Metters, F. E. Weber, G. B. Fields and J. A. Hubbell, Proc. Natl. Acad. Sci. U. S. A., 2003, 100, 5413-5418.

24 M. P. Lutolf and J. A. Hubbell, Nat. Biotechnol., 2005, 23, 47-55.

25 W. Frey, D. E. Meyer and A. Chilkoti, Langmuir, 2003, 19, 1641-1653.

26 N. Nath and A. Chilkoti, Anal. Chem., 2003, 75, 709-715.

27 J. Hyun, W. K. Lee, N. Nath, A. Chilkoti and S. Zauscher, J. Am. Chem. Soc., 2004, 126, 7330-7335.

28 A. Kushida, M. Yamato, C. Konno, A. Kikuchi, Y. Sakurai and T. Okano, J. Biomed. Mater. Res., 1999, 45, 355-362.

29 L. L. Miller and Q. X. Zhou, Macromolecules, 1987, 20, 1594-1597.

30 H. M. Zareie, C. Boyer, V. Bulmus, E. Nateghi and T. P. Davis, ACS Nano, 2008, 2, 757-765.

31 J. Nakanishi, H. Nakayama, K. Yamaguchi, A. J. Garcia and Y. Horiike, Sci. Technol. Adv. Mater., 2011, 12, 044608.

32 Z. Cao, L. Mi, J. Mendiola, J.-R. Ella-Menye, L. Zhang, H. Xue and S. Jiang, Angew. Chem., Int. Ed., 2012, 51, 2602-2605.

33 C. C. A. Ng, A. Magenau, S. H. Ngalim, S. Ciampi, M. Chockalingham, J. B. Harper, K. Gaus and J. J. Gooding, Angew. Chem., Int. Ed., 2012, 51, 7706-7710.

34 J. Auernheimer, C. Dahmen, U. Hersel, A. Bausch and H. Kessler, J. Am. Chem. Soc., 2005, 127, 16107-16110.

35 Q. An, J. Brinkmann, J. Huskens, S. Krabbenborg, J. de Boer and P. Jonkheijm, Angew. Chem., Int. Ed., 2012, 51, 12233-12237.

36 C. C. A. Ng, A. Magenau, S. H. Ngalim, S. Ciampi, M. Chockalingham, J. B. Harper, K. Gaus and J. J. Gooding, Angew. Chem., Int. Ed., 2012, 51, 7706-7710.

37 A. Pranzetti, S. Mieszkin, P. Iqbal, F. J. Rawson, M. E. Callow, J. A. Callow, P. Koelsch, J. A. Preece and P. M. Mendes, Adv. Mater., 2013, 25, 2181-2185.

38 E. Ruoslahti and M. D. Pierschbacher, Science, 1987, 238, 491-497.

39 T. Weidner, F. Bretthauer, N. Ballav, H. Motschmann, H. Orendi, C. Bruhn, U. Siemeling and M. Zharnikov, Langmuir, 2008, 24, 11691-11700.

40 A. E. Hooper, D. Werho, T. Hopson and O. Palmer, Surf. Interface Anal., 2001, 31, 809-814.

41 J. F. Moulder, W. F. Stickle, P. E. Sobol and K. D. Bomben, Handbook of X-ray Photoelectron Spectroscopy, Perkin-Elmer Corp, Eden Prairie, MN, USA, 1992.

42 A. S. G. Curtis, J. Cell Sci., 1984, 71, 17-35.

43 S. Nagrath, L. V. Sequist, S. Maheswaran, D. W. Bell, D. Irimia, L. Ulkus, M. R. Smith, E. L. Kwak, S. Digumarthy, A. Muzikansky, P. Ryan, U. J. Balis, R. G. Tompkins, D. A. Haber and M. Toner, Nature, 2007, 450, 1235-1239.

44 C. T. Jordan and M. L. Guzman, Oncogene, 2004, 23, 7178-7187.

45 P. A. Underwood, J. G. Steele and B. A. Dalton, J. Cell Sci., 1993, 104, 793-803.

46 M. D. Pierschbacher and E. Ruoslahti, J. Biol. Chem., 1987, 262, 17294-17298.

47 K. B. McClary, T. Ugarova and D. W. Grainger, J. Biomed. Mater. Res., 2000, 50, 428-439.

48 M. N. Yousaf, B. T. Houseman and M. Mrksich, Proc. Natl. Acad. Sci. U. S. A., 2001, 98, 5992-5996.

49 Principles of Cellular Engineering: Understanding the Biomolecular Interface, ed. M. R. King, Academic Press, 2006.

50 J. M. Anderson, A. Rodriguez and D. T. Chang, Semin. Immunol., 2008, 20, 86-100.

51 F. Geissmann, M. G. Manz, S. Jung, M. H. Sieweke, M. Merad and K. Ley, Science, 2010, 327, 656-661.

52 B. N. Brown and S. F. Badylak, Acta Biomater., 2013, 9, 4948-4955. 